\title{
Construction of Acculturation-Oriented Teaching Pattern in College Foreign Languages Courses - From Cultural Experience Theory Perspective
}

\author{
Shujun Wang \\ Universidad de Córdoba \\ wsi@sdyu.edu.cn \\ https://dx.doi.org.10.12795/futhark.2019.il4.15
}

Fecha de recepción: 23.05 .2018

Fecha de aceptación: 30.06 .2019

\begin{abstract}
Language is an integral part of culture and culture's big role in language learning can never be exaggerated too much. With worldwide globalization development, it grows to be a heated topic on how to improve foreign language learning outcome by culture teaching. Based on Schumann's Acculturation Model and Moran's Cultural Experience Theory, attempts are made to shed more light on acculturation-oriented pattern construction from cultural experience perspective to guide college foreign language teaching in a more effective way. In addition, pedagogical implications are put forward as well.
\end{abstract}

Keywords: Acculturation Model; Cultural Experience Theory; college foreign language teaching.

Construcción del modelo de enseñanza bajo la teoría de aculturación en cursos universitarios de lenguas extranjeras

Resumen: La lengua es una parte integral de la cultura, y la cultura es imprescindible en el aprendizaje de lenguas. Con el desarrollo de la globalización, se convierte en un tema candente cómo mejorar el resultado del aprendizaje de lenguas extranjeras mediante la enseñanza de la cultura. La investigación está en base del Modelo de Aculturación de Schumann y la Teoría de la Experiencia Cultural de Moran, el artículo analiza desde la perspectiva de la Experiencia Cultural, explica detalladamente cómo se construye el de enseñanza orientada por la aculturación para guiar la práctica de enseñanza de una manera más efectiva. Mientras tanto, también presenta inspiraciones pedagógicas de este modelo. 
Palabras clave: Modelo de aculturación; Teoría de la experiencia cultural; enseñanza universitaria de lenguas extranjeras.

Sumario: I. Introduction. 2. Epistemological foundations and related studies. 3. Acculturation \& cultural experience-oriented teaching pattern construction in college foreign language courses. 4. Pedagogical implications. Conclusion.

\section{Introduction}

Culture is the essence and connotation of a language. Nida (2003) argues language has been seen as an integral part of culture and factors of one culture have a strong influence on the content of the language spoken in this culture. In both second language acquisition (SLA) and foreign language learning, it is inevitable for learners to be confronted with an alien culture. The process of becoming adapted to a new culture is known as acculturation (Brown, 1980). Scholars have been attempting to explain L2 acquisition process in terms of social and psychological factors and acculturation has indeed been a popular topic in a large variety of fields, with linguistics being no exception.

It is undeniable the number of foreign language learners is on the rise dramatically in recent years, however, very few researches have specifically dealt with acculturation level enhancement under foreign language contexts. Therefore, urgent demand is called for to push foreign language teaching forward from acculturation perspective. In this sense, exploration of how to construct acculturation-oriented teaching pattern would much widen and enrich the content scope of second language acquisition. As a mainstream force of language learning in many countries, college students are a group featured by cognitive pro-maturity at a vital world-view formation period, so studies on foreign language teaching focusing on this group bear great academic and practical significance, from which pedagogical implications derived would be invaluable and enlightening undoubtedly. In addition, these attempts would be conducive for population mobility worldwide to promote multiculturalism and cross-cultural communication.

\section{Epistemological foundations and related studies}

\section{I Schumann's Acculturation Model}

Schumann's Acculturation Model is a theoretical hypothesis proposed in the 1970s. Different from former theories, this model does not begin with differences in languages to account for learners' L2 learning differences and it does not trace the reasons from linguistic mechanism in human brains, either. What it dwells upon to interpret learning process is from social and cultural circumstances including social and psychological factors. Schumann holds that acculturation governs the extent to which learners achieve target language norms and second language 
acquisition is just one aspect of acculturation and the degree to which a learner acculturates to the target language group will control the degree to which he acquires the second language. In detail, Schumann (1978a) states "the extent to which learners acculturation depend on two sets of factors (social and affective/psychological factors) which determine their levels of social and psychological distance." Social factors cover the following items: social dominance, integration pattern, enclosure, cohesiveness, size, congruence, attitude and learners' intended length of stay in the target language area. And affective/psychological factors include four aspects: language shock, cultural shock, motivation and ego permeability. Schumann's Acculturation Model was originally intended to account for the acquisition of an L2 by immigrants in majority language settings (Ellis, 1994). That is, the model is a proposal for second language context theoretically and specifically excludes learners who receive formal instruction. Later, some certain factors, mainly in view of scarce empirical proof to testify the model's validity, made Schumann determined to widen its application. Schumann (1986) admitted "The Acculturation Model may also be applicable to other groups.... All these filters shed light on the model in different ways." Widened applicable scope and an account of cognitive processing taken into account in 1990 are considered as two main breakthroughs of the model.

With worldwide international openness, more and more people are required to have a command of another language other than their mother tongue for work or life purpose and a large number of them are under foreign language backgrounds rather than in naturalistic settings. No matter learners are in native or target language environment, they are certain to be exposed to a new culture since culture is disseminated by language. And all language learners are bound to be confronted with the same question: how to get acculturated into target culture and community? As a matter of fact, the two sets of factors which determine acculturation level (social distance and psychological distance) are suitable for foreign language learners in the same way, with the only divergence being parameter values appearing somewhat different. Based on the above, Schumann's model is also conducive for foreign language settings with formal schooling instruction and acculturation would play a bigger role in foreign language teaching productivity. As a result, how acculturation affects foreign language proficiency positively merits more attention.

Schumann is a representative of environmentalist approach to SLA, which denies the contribution of innate abilities and attempts to explain the learning process in terms of external factors. His Acculturation Model is one of the most influential theories from sociolinguistic perspective, which provides a valuable context of theory toward second language acquisition. Farhady (I98I) is convinced Schumann's Acculturation Model takes into consideration the most important 
factors which may be involved in SLA. Norton Pierce (1995) highlights the strengths of Schumann's model in social and cultural contexts of language learning without neglecting the role of individuals during the process. It recognizes the importance that must be placed on regular "contact" between language learners and speakers of the target language for successful language learning to take place.

Widespread internationalization stimulate scholars to reflect on how language enhancement is linked with cultural identity with abundant achievements having been made and here only a few are named as follows. Kefeng Fu (2015) presents a brief description of the history, dimensions, and subjects of acculturation study. Vahid Rafieyan, Maryam Orang, Maryam Bijami, Maryam Sharafi Nejad \& Lin Siew Eng (2014) explores the acculturation attitudes of a cohort of Iranian undergraduate students of English as a foreign language and his findings indicate sojourners tend to adopt integration and assimilation strategies as their acculturation attitudes, shedding much light on the related studies. Wu Ying (20I4) argues in his master's thesis that languages and cultural identities are interactive and can promote each other. Samples in his investigation (college students from Shanghai, China) adopt integration strategy in the process of acculturation and progress of learning a foreign language results in the breakthrough of cultural boundaries and the development of intercultural competence. Lai, C (20I5) generates two conceptual models to describe how cultural identification affects language learning as hypothesized in different theories on identity and second language learning, and tests these two hypothesized models in immigration context of Hong Kong.

Many scholars have elaborated how acculturation affects EFL (English a foreign language) college teaching development. Xu Yang (2013) probes into measures of cultivating students' acculturation ability in college English teaching. Duan Xiaohan (20l4) interprets foreign language learning from acculturation perspective in detail. Zhang Lijun (2015) elaborates what enlightenment can be obtained for college English teaching from Schumann's Acculturation Model theory. Both abundant theoretical and empirical achievements have arisen in this field, but the number of studies dealing with concrete acculturation-oriented teaching patterns in college foreign language courses is apparently not large enough to lay out a clear picture showing how acculturation idea-based teaching mode is implemented. Acculturation surveys focusing on foreign language learners particularly college students were mainly conducted before the year of 2015 and much fewer investigations can be found after 2015.

\subsection{Moran's Cultural Experience Theory}

In terms of culture teaching pattern, Cultural Experience Theory proposed by Patrick R. Moran in 200 I is one of the most popular and widely accepted, with 
its core philosophy being five key elements that consist of culture: cultural products, practices, perceptions, communities and individuals. In order to equip learners with a comprehensive command of target language, Moran advocates establishing cultural experience-based teaching model covering several interactive processes among four factors: content cognition (also called cultural information), method cognition (i.e., cultural practices), view cognition (i.e., cultural views) and self-cognition (i.e., cultural self-awareness).

The focal point of Cultural Experience Theory is to provide various culturerelated activities for language learners to get involved in, to perceive cultural behaviors from, to make cultural reflections on and to grasp cultural content with the final aim of new culture view formation (to both native and target language). Simply speaking, Cultural Experience Theory is a philosophy starting from practice, proceeding to theory and progressing towards practice again as a cyclical and dynamic whole, as shown in chart I.

Chart I. Rationale of Cultural Experience Theory
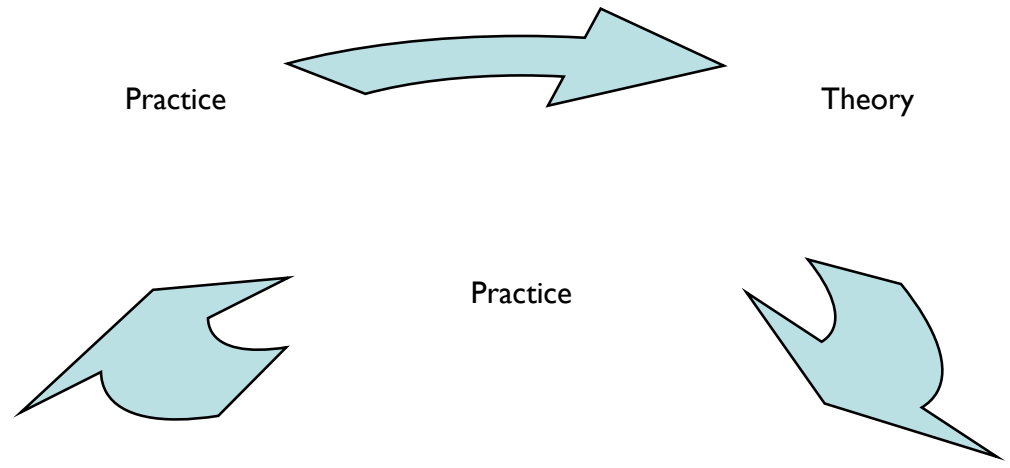

Enlightened by Moran's cultural experience perspective, educators conducted abundant researches in practice. Huang Huerli (2008) reflects current situation of culture teaching in Chinese colleges back in 2010's, and countermeasures are put forward in addition. Chen Xiyan (2009) introduces and dissects Moran's major culture theoretical views, particularly dwelling upon how to strengthen cultural experiences and cultural practices in language courses. With Moran's cultural practice perspective as the main source, Su Guangcai \& Meng Xin (20I4) put forward a set of teaching methods dealing with cultural differences in college English courses and testify their validity. All of these studies introduce Moran's core idea --- practice into foreign language teaching circumstances, but 
what cannot be denied is these attempts are more theory-centered than concrete teaching methodology-oriented. For this reason, it bears great significance to explore how to implement Moran's Cultural Experience Theory in classrooms with step-by-step procedures. Similarly, much fewer post-2015 investigations can be found regarding teaching guided by Moran's Culture Experience Theory. With circumstances having changed rapidly in recent years and a dramatically rising number of foreign language learners, it permits no delay to probe into how to carry out culture teaching in college foreign language classrooms scientifically, particularly combining the guidance of Schumann's Acculturation Model.

\section{Acculturation \& cultural experience-oriented teaching pattern construction in college foreign language courses}

3.I Methodology of acculturation \& cultural experience-oriented teaching pattern construction

\section{I.I Knowing what -- Content cognition}

Content cognition in Moran's theory refers to acquire more cultural knowledge by collecting related information. That is, learners immerse themselves into target language to understand specific cultural behaviors with a large amount of exposure to target culture practices. Besides target culture and native culture concepts, learners' individual experiences should be taken into consideration as well. After learners are imbued with a great deal of target cultural information, they will unconsciously place themselves into a position of cultural comparison, where individual experiences come into play to a large extent. For instance, different extent of affinity held by individuals to target culture will yield different language acquisition outcome. That's why individual differences exist facing the same information input.

The imbued cultural information forms "what to know" and they constitute "input" at the chain of cultural knowledge operation cycle, so quality of cultural information appear vital under foreign language learning contexts. As the initiator of the chain to activate cultural interactions, quality and quantity of the input deserve more attention. More efforts are expected to make by teachers to make authentic target culture resources more accessible to students. "Contact" is also what Schumann Acculturation model claims, coinciding with what is required by cultural cognition ("knowing what"). Only with abundant qualified "contact" with native speakers and resources, can language learners are endowed with much genuine "input" to form satisfactory basis of language acquisition.

With modern technology development, a large quantity of qualified "contact" has been made possible thanks to internet widespread popularity. Abundant visual and audio resources are available for language and culture learning 
to make learners fully acquaint with "what to know". With plenty of "what to know", how to make them aid language learning effectively and turn out to be conducive to shorten learners' social and psychological distance? On one hand, several aspects of language competence are focused on in college foreign language classrooms: listening, speaking, reading, writing and translating. Naturally it occurs to teachers that they can introduce these resources to organize activities in various forms to render language skill development. On the other, resources may as well be made as "corpus" for affiliation accumulating purpose. That is, teachers may as well consciously guide students to build kinship to the target culture and consolidate their ethic pride at the same time. In this way, resources are made use of to the full extent and a perfect combination between Schumann's Acculturation Model and Moran's Cultural Experience Theory perspective is realized in foreign language classrooms.

\section{I.2 Knowing how -- Cultural practices}

At this interaction link, learners are to grasp connotation of the target culture by gradually immersing themselves into a series of cultural practices. Generally, they need to know what to say and how to express, what to do and how to act. Strictly speaking, these are to be ideally achieved in naturalistic settings where authentic cultural behaviors happen. Then how to perceive deep beliefs and values of the target culture under foreign language learning contexts? The key lies in attempts to simulate native cultural environments for beneficial input and practices. Teachers, as class activity organizers and planners, are suggested to create quazi-native contexts in which learners may have access to act and perform similarly in target cultural surroundings. Besides, native speakers such as foreign teachers and exchange overseas students are available to exert influence on foreign language learners positively, who constitute another group of treasurable resource. Meanwhile simulated conditions are suggested to be organized on a regular basis for cultural practices as well to obtain first-hand experiences.

\section{I.3 Knowing between -- Cultural views}

Learners are supposed to grasp basic comprehension of target culture and probe into, analyze, interpret cultural phenomena to understand its behaviors and attitudes ultimately. Cultural concepts embrace two facets: emic and etic views. Besides, disparity of values and beliefs between the two is mainly concerned as well in terms of cultural perception. Emic values correspond to the ideas held to one's native culture and etic to target culture. According to Schumann (1986), acculturation falls into two types: For type I acculturation, the learner is socially integrated with target language (TL) group, and as a result, develops sufficient contacts with TL speakers to enable him to acquire the target language. In addition, he is psychologically open to the TL such that input to which he is exposed 
becomes intake. The second type acculturation has all the characteristics of type I, but in this case, learners regard target language speakers as a reference group whose life style and values he consciously or unconsciously desires to adopt. Both types of acculturation are sufficient to cause acquisition of the TL and adoption of the life style and values of the TL group is not necessary for successful acquisition of the TL. Correspondingly, three integration strategies come into being: assimilation, preservation and acculturation ("adaptation" by Schumann in 1986). If the second language learning (2LL) group assimilates, then it gives up its own life style and values and adopts those of the target language group. This strategy maximizes contact between the two groups and enhances acquisition of the target language. If the $2 \mathrm{LL}$ group chooses the preservation strategy, then it maintains its own life style and values and rejects those of the TL group. This situation creates social distance between the two groups and makes it unlikely that $2 \mathrm{LL}$ group will acquire the TL group's language. If the $2 \mathrm{LL}$ group chooses acculturation/adaptation as its strategy, then it adapts to the life style and values of the target language group, but maintains its own life style and values for intragroup use. This particular acculturation strategy yields varying degrees of contact between the two groups and thus varying degrees of acquisition of the target language. Schumann's acculturation theory has never been lonely in advocating cross-cultural communication and integration. Lambert's social and psychological model put forward in 1974 focuses on the relationship between ethnic identity and target culture affinity, which is elaborated by the following chart.

Chart 2. Lambert's social and psychological model

Attitudes towards

Native culture Target language culture

Additive bilingualism

/acculturation/adaptation

Subtractive bilingualism/ assimilation

Semilingualism

Monolingualism (preservation)

Key: + = positive attitudes

= negative attitudes 
Lambert (1974) distinguishes bilingual states as additive bilingualism and subtractive bilingualism, coinciding with Schumann's adaptation/acculturation and assimilation strategy. Both Schumann's and Lambert's model lend much light to acculturation's role in second language learning. Under foreign language circumstances with formal instruction, it is unlikely for learners to develop semilingualism strategy coined by Lambert, so only adaptation, assimilation and preservation strategies will be dwelt upon here. In college foreign language classrooms, teachers are suggested to lead students to hold affinity towards both their native and the target culture because every culture has its own strengths and that's why multiculturalism has been flourishing worldwide. Only learners remain affiliated to both cultures, can learning outcome be optimized to the largest extent. Any forms of subtractive bilingualism (assimilation) and monolingualism (preservation) will hinder language acquisition, let alone semilingualism. Teachers should spare no efforts to encourage students to find out shining spots of each culture, thus a favorable, tolerant and generous culture view is prone to be established. With kinship and shortened distance towards both cultures, adaptation/acculturation strategy is possible to be built up to achieve utmost language proficiency finally.

In the world today, cultural diversity is advocated and additive bilingualism/adaptation/acculturation pattern is supposed to be the mainstream for foreign language learners when confronted with any alien cultures. Stable cultural view system will form with cultural analysis, cultural comparison and cultural exploration, during which teachers' role are strongly recommended to come into play. Based on relevant themes of the teaching content, more helpful and appropriate resources, particularly target culture-attached materials, should be collected for practice purpose. Thanks to modern technology development, various easily-reaching platforms with multifold information, like Wechat, $\mathrm{QQ}$, are accessible for cultural dissection and appreciation. Students can be guided to keep an eye with wisdom to find out shared commonality and respect disparity of the two cultures. It is undeniable that culture and politics are intertwined and different interest held by different countries do lead to possible conflicts among each other, while learners should remain objective, rational and neutral constantly facing cultural shocks. Teachers are encouraged to observe learners' emotion to target culture, analyze their inner conditions, mediate their psychological state and help override their ego mental barrier to establish an all-round cultural mindset. Much insight and inclusiveness are needed when learners view the two different sets of cultural rules, regulations, doctrines, thinking styles and patterns to conduct cultural comparison. During this process, learners can trace culture origins, promote cultural understanding and deepen ideas to both cultures in essence. The ideal result is learners construct affiliation to target culture gradually on one hand and consolidate former conviction to their mother culture on the other. Thus, 
their world view turns out to be more complete, harmonious and generous afterwards. At the same time, learners' personality and value system would be shaped as well, which would undoubtedly be beneficial for their future development.

Brown (1980) proposed four-stage theory involved in acculturation evolution: euphoria, culture shock, gradual recovery and full recovery, indicating how acculturation takes place during cultural comparison. Target-culture view formation undergoes the following procedures accordingly: After experiencing initial excitement, emic and etic cultural concepts conflict most with each other during cultural shock stage. Later, divergence in values and beliefs between the two would go dull until fade ultimately. When language learners move on from cultural stress to recovery, they are on the way to being more acculturated and better acculturation will bring about more linguistic enhancement. During the final stage -- full recovery, emic and etic cultural views would coexist with most satisfactory harmony, in which optimal cultural and language outcome would be realized. Foreign language teachers' classroom mission at this link is to aid learners to make objective cultural comparison to foster kinship to both cultures, and then a sound and healthy cultural value system comes into being naturally. In doing so, learners know what lies between two cultures and how to seek common ground while reserving differences to form one's mature cultural cognition system.

\section{I.4 Knowing oneself - Cultural self-cognition}

The ultimate goal of cross-cultural communication is to equip learners with rational cultural views to comprehend realistic world deeply and sharply. For this reason, individuals should cultivate their independent thoughts, ideas and philosophy, which can be achieved at the final interaction link: cultural selfcognition. Self-cognition refers to autonomous reflection one makes to establish his fair self-awareness. It is the highest level of cultural experience theory, where learners are supposed to form their own individual world view including response to target language and adaptive feedback to target culture behavior. Besides, learners' individual monitoring, exploring and expressing ability are included as well. Rationale among the four interaction links can be interpreted in this way: Culture information forms the basis, with learners' participating cultural practices being the premise, and then learners obtain innate cultural self-cognition by cultural comparison.

Sociocultural theory (SCT) in the field of second language acquisition holds learning is a mediation process, during which regulation received from others transfers to self-regulation. Every advanced human psychological function follows two-plane development pattern: interpsychological plane and intrapsychological plane. At plane I, interpsychological phase, learners need exterior aid from others 
to scaffold learning outcome, i.e. receiving cultural information and provided with various culture-related practices to get involved into with the help of "outsiders", like parents, tutors or veterans with sophisticated experiences. Plane II, intrapsychological phase is a process in which learners avail obtained information to make active and creative inferences after they are able to self-suffice to do so. Successful learning cannot be realized unless learners stride from interpsychological to intrapsychological activities. Besides, SCT holds learning, in essence, is achieved by internalization, a process during which human beings' utterances are turned into psychological products to mediate their psychological activities, then to control the complicated mental function.

Only with internalized self-awareness, can learners grow active and free to comprehend realistic world in an objective way. Realization of cultural selfcognition proves that learners have mastered innate cultural views to analyze both native and target cultural behaviors. While new target cultural value system forms, the original native view has also been in constant dynamic perfection of being reshaped and reinterpreted. College foreign language teaching is a key way with which learners are aided to promote their internalization of acculturation awareness. Teachers are supposed to stimulate students' optimal innate acculturation consciousness and promote their positive perception toward target culture system. Ultimately, learners build up their own self-cognition system resulting in a favorable attitude to both cultures.

\section{I.5 Interactive relationship among four cultural components}

Relationship among the four components: cultural information, cultural practices, cultural views and cultural self-cognition is displayed in Chart 3. Initially, learners are imbued with cultural information, the basis of latter parts, constituting "what to know" about target culture. Through the following "cultural comparison" between emic and etic views, their original concepts will be shaped until new value systems are established towards the two cultures. Ultimately, one's cultural selfcognition forms through internalization process. With the formed self-cognition, they know what to say, how to express, what to do and how to act in realistic practice. Thus, a full cycle of Cultural Experience Theory is fulfilled. The cycle is interpretable from another different angle: Cultural practices can be considered as the initial activator, into which learners get involved and from which they absorb cultural information. This stage provides abundant "input" for learners' to digest, then followed by cultural comparison between emic and etic views. Finally, selfcognition forms as the end to accomplish the whole cycle, followed by another new round of cultural practices. 
Chart 3. Interactive relationship among cultural information, cultural practices, cultural views and cultural self-cognition

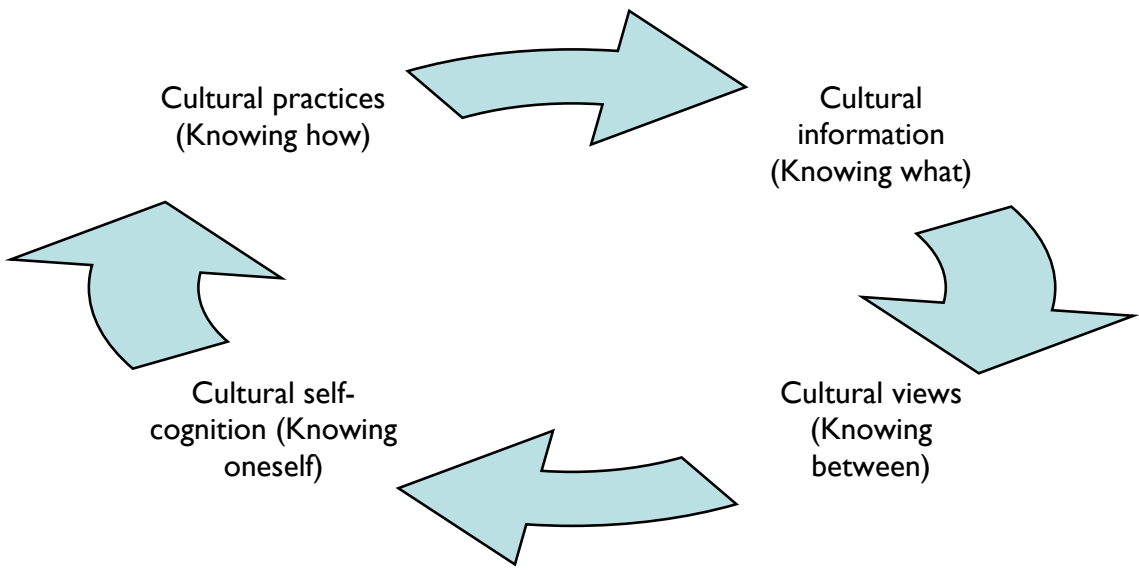

How to introduce acculturation idea into college foreign language classroom activities, guided by Cultural Experience Theory?

\subsection{Acculturation \& cultural experience theory-oriented teaching procedures}

\subsection{Input-oriented teaching objectives}

Broadly speaking, several main objectives of foreign language teaching are included necessarily as follows:

I. Command of alien cultural information

Target cultural information forms an indispensable part in language learning, from which learners derive their own cultural view systems.

2. In-depth values beneath cultural information

What follow next is dissection, appreciation and analysis of information input. Cultural values are displayed by various "superficial" behaviors, which need to be further probed into and explored. Guided by organized classroom activities, learners should later be provided with platforms to confer, discuss and summarize values behind cultural appearances. Only with inner and deeper comprehension, 
would learners be committed to approaching target culture with much insight. It should be pointed out value system dissection should be carried out objectively and comprehensively. In alien culture interpretation, both teachers and students should bear in mind human personality is diversified and it is not rational for one to label an ethic group based on partial features displayed by some certain individuals. Uniqueness deserves respect, but it can never be an excuse for sweeping generalizations.

\section{Cultural comparison ability}

Exposed to cultural information attached to native and target culture, learners now need to make comparison to find out their similarities and differences between the two. In this process, two mentalities are worthy for special attention to avoid: ethic arrogance and self-inferiority. Both trends will yield negative impact on sound and healthy cross-cultural communication ability development and thus hinder acculturation's positive effect in language learning.

\subsubsection{Teaching activities design}

With objectives fixed, next a series of teaching activities are designed and several points highlighted.

I. More importance attached to quality of culture information input

Authentic target language resources reflecting majority cultural characteristics would be ideal for classroom instruction. Teachers are strongly recommended to keep a sharp eye on the "input" quality.

\section{More efforts made for simulated target cultural settings}

Simulated target cultural settings should try to be achieved since they are optimal for foreign language settings, under which learners are not blessed with genuine contexts for pure cultural practices. These can be realized to a large extent currently due to intense population mobility because rapid globalization development makes simulated target culture communities possible to be established. With abundant information via Internet, a quazi-target language sense is also possible to obtain in classrooms. Besides, native foreign language teachers can co-teach with non-native teachers, with the former taking linguistic and cultural immersion responsibility and the latter grammatical task, etc.

\section{More opportunities provided for self-cognition}

As has been mentioned, self-cognition is the highest and ultimate goal among several cultural interaction links. Based on cultural information input, cultural practices and cultural cognition, its realization is determined largely by learners' internalization process. As a kind of output form, teachers are encouraged to 
provide plentiful classroom opportunities for learners to present themselves, through which their affiliation to target language and culture will be accumulated step by step.

\subsubsection{Reflection on acculturation cultivation}

With the above two steps accomplished, it is time for teachers to reflect outcome and effectiveness of the acculturation \& cultural experience-oriented teaching pattern. Students' classroom behavior can testify how much they have got involved into target language learning, what attitudes they hold towards their mother and target culture, whether their social and psychological distance are prone to be bettered and so on. Besides, teachers should spare no efforts to strengthen students' understanding to both cultures, which is not only helpful to train their ethnic pride, but conducive to uphold a favorable attitude to target culture. It should be noted attitudes towards a culture should be separated from politics. As what has been illustrated, different countries would conflict with each other unavoidably in the modern world today, however, culture itself is a reflection of human wisdom and every culture bears civilization and progress marks. Learners need to be more tolerant, generous and inclusive, which is not only indispensable for culture appreciation, but necessary for one's healthy personality and sound world view development.

Schumann's Acculturation Model emphasizes social factors' role affecting L2 acquisition and Moran's Cultural Experience Theory furthers to elaborate how to realize interaction among culture's several components. The following two charts display how acculturation-oriented teaching pattern from cultural experience perspective is constructed, which can facilitate college foreign language teaching and learning. 
Chart 4 Construction of acculturation-oriented teaching pattern from cultural experience perspective

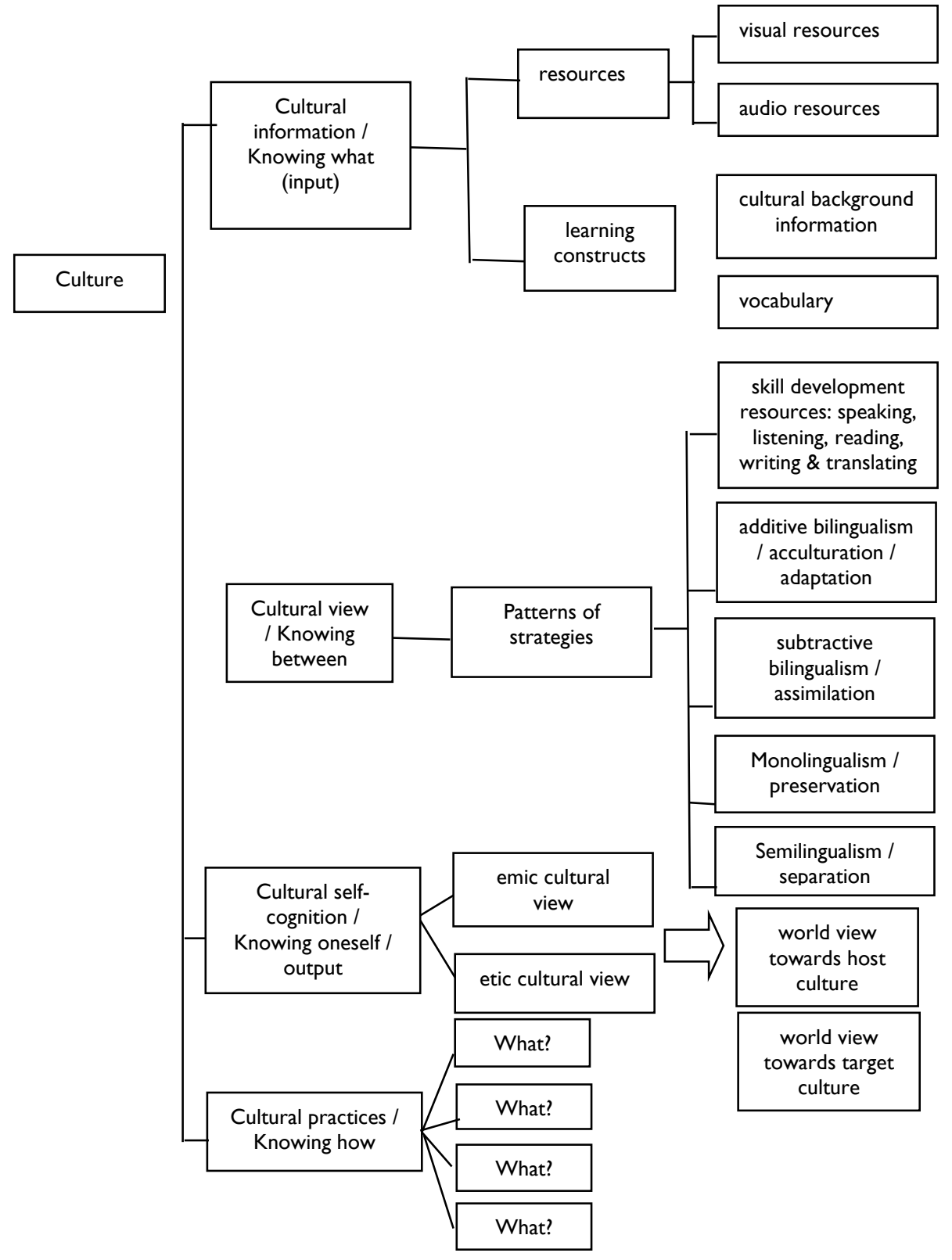


Chart 5 Acculturation \& cultural experience theory-oriented teaching procedures

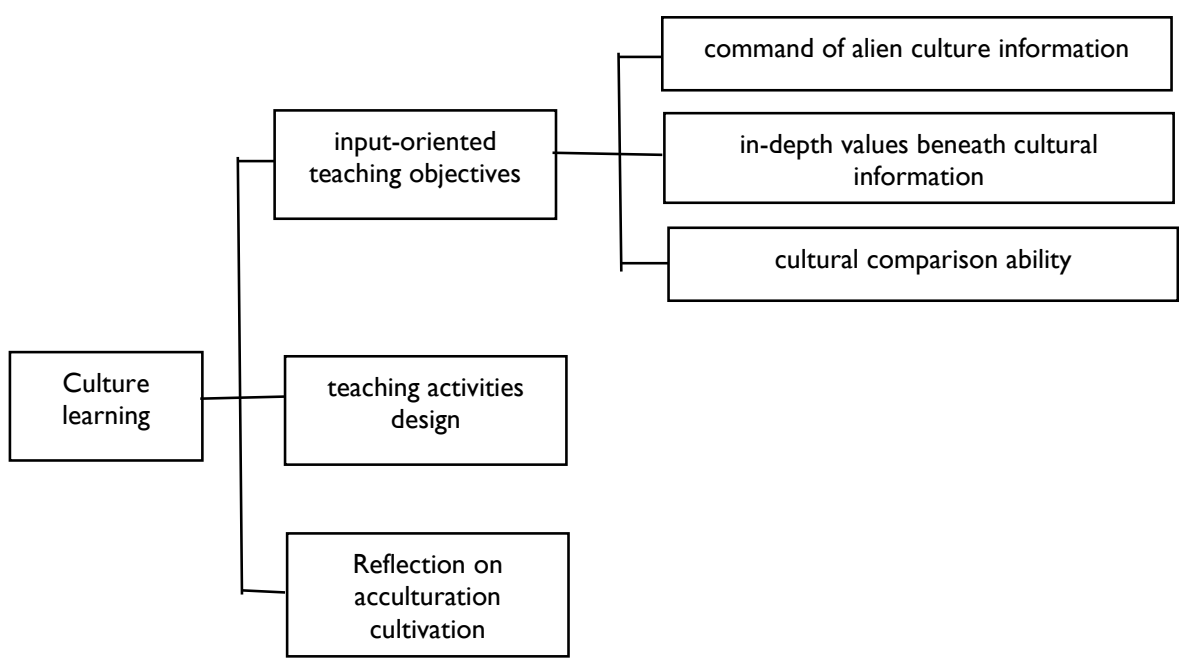

\section{Pedagogical implications}

\section{I Preemption effect}

It makes new challenges for teachers to construct acculturation-oriented teaching pattern from cultural experience perspective in college foreign language courses. Traditional role of sole "teacher" is required to transform into an effective culture learner, experiencer and disseminator.

Cognition of teachers will produce "preemption effect" which influences their students to form initial attitudes towards target culture. Therefore, teachers should be cautious enough about the effect and they are expected to have a command of diversified cultural backgrounds. Objective, rational and scientific attitude to alien cultures is also necessary, which sets higher professional demand for college foreign language teachers today. In this way, a more favorable stance to target culture will be transferred to students, which is profitable for their cognitive development.

\subsection{More emphasis on Social Distance's power than that of Psychological Distance}

Language learning settings can be good or bad according to the two sets of factors determining learners' acculturation levels. Generally, social factors are more objective since they are fixed and cannot be changed easily, so it is psychological/affective factors that play a bigger role in acculturation enhancement 
under foreign language contexts. For this reason, teachers may as well focus on affective factors to help students shorten psychological distance affiliated to the foreign target language. The first factor covered by psychological parameters is language shock, which is interpreted as a kind of fear learners feel because they are afraid to appear comic when attempting to speak a second or foreign language. In classrooms, teachers are supposed to introduce encouragement policy to stimulate students to speak without hesitation and frustration. Cultural shock can be defined as anxiety resulting from disorientation encountered upon entering a new culture. Under foreign language settings where cultural shock is much less fierce, teachers can still provide appropriate resources and cases to buffer students' fear and rejection to the alien culture. Hence, they would overcome linguistic and cultural conflicts to be more confident to pursue bilingualism. The third affective parameter, motivation, involves learners' reasons for attempting to acquire a second/foreign language. It has generally been thought integrative motivation is more powerful than instrumental motivation. But foreign language learners' integrative motivation is not necessarily strong enough for self-stimulation because most of them do not intend to integrate with native speakers. But utilitarian stimulation still works somewhat under foreign language contexts, which can not be denied. Teachers should analyze students' psychological state and their individualistic demands to select appropriate motivation to push them forward. For instance, various kinds of certificates, the wish to go abroad can exert motivating power in language learning. There's much that can be done as to ego permeability, the capacity of being influenced by other cultures. Proof shows language ego boundaries are permeable in early stages of development, but later they become fixed and rigid. In this case, teachers should collaborate with learners to make joint efforts by aiding them to stride over ego psychological barrier as soon as possible.

\subsection{Enlightenment for curriculum design}

The aim of foreign language teaching is to cultivate students' communicative talent to participate target cultural activities successfully, i.e. getting involved into target cultural practices with formed cultural self-cognition at ease. Consequently, combination of language teaching and the culture of target language community must be taken into account when college curriculum is designed. It deserves much attention to make it comply with language acquisition rules on one hand, and follow acculturation concept, combined with cultural experience theory on the other to improve language teaching productivity.

\section{Conclusion}

It has been a popular wisdom that language and culture are interrelated as a whole and they are inseparable from each other. Schumann's Acculturation Model and Moran's Cultural Experience Theory shed much light on college foreign 
language teaching and learning. How to fulfill them in practice scientifically is determined by specific circumstances and backgrounds. It bears great significance to explore workable teaching patterns for more effective language and culture learning outcome.

\section{Bibiliography}

Brown, H. (1980). The optimal distance model of second language acquisition. TESOL Quarterly, I4:I57-64.

Chen Xiyan.(2009). Language Learning as Cultural Practices --- Analysis on Moran's Teaching Language Culture Teaching Perspective [J] , Journal of Qing hai Normal University (Philosophy and Social Sciences), No.3.

Duan Xiaohan. (20I4). Foreign Language Learning from Acculturation Perspective []] . Journal of Hunan University of Science and Engineering. Vol.35, No.I.

Ellis, R. (1994). The study of second language acquisition. Oxford: Oxford University Press.( $2^{\text {nd }}$ ed., 2008$)$

Farhady, H. (198I). On the plausibility of second language acquisition models. Second Language Acquisition Research Forum (SLRF Meeting). University of California, Los Angeles.

Graham, C. R. \& Brown, C. (1996). The effects of acculturation on second language proficiency in a community with a two-way bilingual program. The Bilingual Research Journal. 20, 2, 235-260.

Huang Huerli \& Xu Xiaoshu (2008) Reflection and Countermeasures of Current Culture Teaching Situation. Social Sciences Review. Vol 2. PP. 258-259.

Kefeng Fu. (20I5). A Brief Literature Review on Acculturation Strategies of Overseas Students, English Language Teaching, Vol.8, No.8.

Lai, C; Gao, F \& Wang, Q. (20I5). Bicultural orientation and Chinese language learning among South Asian ethnic minority students in Hong Kong, International Journal of Bilingual Education and Bilingualism, Vol. 18 No. 2, p. 203-224.

Lambert, W. (1974). Culture and language as factors in learning and education, in F. Aboud and Meade (eds.)

Moran Patrick R. Teaching Culture: Perspective in Practice [M] . Beijing: Foreign Language Teaching and Research Press, 2009.

Nida, E.A. (2003). Language and Culture. In S. Mejiri (Ed.) Traduire la Langue, Traduire la Culture (p. 193). Paris: Maisonneuve and Larose.

Norton Pierce, B. (1995). Social identity, investment, and language learning. TESOL Quarterly, 29(I), 9-31.

Schumann, J. (1978a). 'The acculturation model for second language acquisition' in R. Gingras (Ed.) Second language acquisition and foreign language teaching (pp. 27-50). Arlington, VA: Center for applied linguistics. 
Schumann, J. (1986). Research on the acculturation model for second language acquisition. Journal of Multilingual and Multicultural Development, 7, 379-392.

Su Guangcai \& Meng Xin. (2014). An Empirical Study on College English Cultural Difference Teaching Methodology, Foreign Language and Literature, Vol.30, No.l.

Vahid Rafieyan, Maryam Orang, Maryam Bijami, Maryam Sharafi Nejad \& Lin Siew Eng (20I4). Language Learners' Acculturation Attitudes, English Language Teaching; Vol.7, No.I.

Wu Ying (20 I 4). A Study of Cultural Identity Development in Foreign Language Learning [D]. Shanghai Normal University.

Xu Yang. (2013). A Study on Acculturation Ability Cultivation in College English Teaching. Journal of Chifeng College. Vol.29, No.9.

Zhang Lijun. (20/5). Implications to College English Teaching from Acculturation Model Perspective, Pedagogy Exploration And Practice. Vol 153. 
